\title{
Programa de suporte comunitário: alternativa Para o trabalho DO ADULTO DEFICIENTE MENTAL ${ }^{1}$ \\ ASSESSMENT OF A COMMUNITY SUPPORT WORK PROGRAM FOR MENTALLY \\ RETARDED ADULTS
}

\author{
Eliane Aparecida Campanha ARAÚJO2 \\ Giovana ESCOBAL ${ }^{3}$ \\ Celso GOYOS ${ }^{4}$
}

\begin{abstract}
RESUMO: este trabalho de pesquisa desenvolveu e avaliou um procedimento de formação de um grupo de planejamento de programa de suporte comunitário, visando atender a necessidade de preparação, encaminhamento, colocação e apoio ao jovem e adulto com deficiência mental no ambiente natural de trabalho. O procedimento procurou integrar as diferentes agências já existentes na comunidade para planejar, desenvolver, implementar e avaliar diversos serviços relativos à formação do deficiente mental para o trabalho, desde a transição da escola especial para o trabalho até a colocação e manutenção em uma ocupação remunerada. Foram convidados para participar no grupo, representantes de setores expressivos da comunidade local. Sete passos referentes à organização grupo foram implementados: 1) constituição da equipe; 2) identificação e descrição das necessidades da comunidade; 3 ) identificando os membros da equipe; 4 ) inicio do planejamento; 5) definição da missão do grupo; 6) avaliação de oportunidades de mudança e 7) estabelecimento de objetivos e atividades. Os resultados apontaram onze aspectos de conteúdo para análise do processo realizado. Observaram-se grandes dificuldades na manutenção do grupo, o que impediu que o procedimento fosse aplicado até o final do planejamento. Foi apresentado uma análise das possíveis razões dessas dificuldades, e proposto um curso para divulgar e discutir o conceito de planejamento de programa de suporte para o trabalho do deficiente mental adulto e estimular novos grupos em outras comunidades.
\end{abstract}

PALAVRAS-CHAVE: programa de suporte comunitário; adultos deficientes mentais; trabalho.

ABSTRACT: this research attempted to develop a community program planning to meet the needs derived from the development, training, placement and support of mentally retarded adults working in the natural environment. Community program planning requires the integration of several agencies in the community in order to plan, implement and assess services. Representatives of several community agencies participated. Seven steps leading to the organization of the proposed group were implemented: 1) starting the team; 2) defining community needs; 3) identifying team members; 4) starting the planning meeting; 5) defining the mission of the community program planning group; 6) evaluating the opportunity to change; 7) proposing objectives and activities. The results showed that the objectives proposed were partially met. However, great difficulties were observed in group maintenance. The proposal had to be interrupted before the end of the program. The reasons for such difficulties were analyzed and publication and discussion of the concept of community program planning teams was proposed to meet the needs involved in supporting the work of mentally retarded adults. It was also proposed that the procedure be replicated in different communities, to control for local variables, and as an incentive to the development of new work groups.

KEYWORDS: community support program; mental deficiency; adults special education for professional preparedness.

${ }_{1}^{1}$ Os autores agradecem à CAPES, por uma bolsa PRODOC à primeira autora e à FAPESP pelo apoio financeiro
através de auxílio à pesquisa. Durante a execução do trabalho, Giovana Escobal desfrutou de bolsa de Inicia-
ção Científica da FAPESP e Celso Goyos desfrutou de bolsa de pós-doutorado no exterior da CAPES.
${ }^{2}$ Programa de Pós-graduação em Educação Especial; Laboratório de Aprendizagem Humana, Multimídia
Interativa e Ensino Informatizado (LAHMIEI), Departamento de Psicologia, UFSCar-araujoeac@yahoo.com.bb.
${ }^{3}$ Programa de Pós-graduação em Educação Especial; Laboratório de Aprendizagem Humana, Multimídia
Interativa e Ensino Informatizado (LAHMIEI), Departamento de Psicologia, UFSCar-
giovanaescobal@yahoo.com.br
${ }^{4}$ Programa de Pós-graduação em Educação Especial; Laboratório de Aprendizagem Humana, Multimídia
Interativa e Ensino Informatizado (LAHMIEI), Departamento de Psicologia, UFSCar - celsogoyos@hotmail.com 


\section{INTRODUÇÃo}

Apesar da política inclusiva em vigor, a maior parte das oportunidades de formação para o trabalho do indivíduo deficiente mental se dá em escolas especializadas através de oficinas que têm como objetivo principal preparar o deficiente mental para exercer trabalho produtivo em ambiente protegido ou competitivo (GOYOS, 2001; TANAKA, 2001). Alternativas ao trabalho protegido mais compatíveis com as políticas inclusivas tais como: equipe móvel e emprego apoiado têm sido amplamente divulgadas (RUSCH, 1990; GOYOS, 1995; KREGEL; WEHMAN, 1997). No entanto, fatores comuns à nossa realidade dificultam a viabilização dessas, assim como a de outras eventuais alternativas de formação para o trabalho.

Primeiramente, a noção de que o diagnóstico preciso e imediato de uma condição anômala é de fundamental importância para o sucesso do atendimento é consensual na área de saúde. Esta noção também se estende, em tese, para a área de atendimento do indivíduo com deficiência mental. No entanto, não é prática corrente na área de educação deste indivíduo para o trabalho (GOYOS, 2001). Em segundo lugar, ao iniciar a educação formal, a criança com deficiência mental, por conta do diagnóstico tardio e fatores educacionais e sociais, possui uma defasagem comportamental grande em relação ao que se espera do seu repertório de entrada, assim como em relação ao repertório de seus colegas, tratando-se de escola inclusiva. Essas duas condições combinadas freqüentemente tornam o indivíduo mais vulnerável a discriminações, prejudicam e até mesmo inviabilizam sua educação fundamental. Apesar dos esforços institucionais empregados, o fracasso escolar é o resultado mais freqüentemente obtido com esta população. Muitos desses indivíduos abandonam a escola para entrar no mercado formal ou informal de trabalho (GOYOS, 1995). Em terceiro lugar, nas escolas inclusivas não se discute ainda a fase de transição do indivíduo com necessidades especiais para o trabalho e, em quarto lugar, há o aspecto de preparação dos responsáveis pela formação do indivíduo com necessidades especiais para o trabalho.

Os responsáveis pela tarefa de preparar a pessoa com deficiência mental para o trabalho comumente se deparam com demandas que requerem, principalmente, formação específica na área de ciências humanas. Além disso, esta tarefa requer múltiplas habilidades, de diferentes áreas do conhecimento: economia, sociologia, psicologia, contabilidade, marketing, treinamento de pessoal, entre outras e, dificilmente, os indivíduos poderão estar preparados, ou poderão ser preparados para desempenhar tal papel (EVERSON; MOON, 1990). Nem mesmo uma instituição, por maior ou mais organizada que seja, vai poder desempenhá-lo independentemente, porque a tarefa transcende as possibilidades institucionais em função das maneiras pelas quais essas instituições estão organizadas. Nota-se, portanto, que a sobrecarga enfrentada pelos responsáveis pela formação do indivíduo com necessidades especiais para o trabalho é enorme. 
Uma sugestão, proposta por Everson e Moon (1990), é a de aproveitamento de esforços já existentes, através da implantação de programas de intervenção na comunidade, que levem em conta o aproveitamento de grupos prestadores de serviços já atuantes na comunidade e a criação de novos grupos em função desses esforços combinados.

Para Everson e Moon (1990), um planejamento racional de programa na comunidade requer a integração de grupos de diferentes agências locais já existentes para planejar, desenvolver e implementar programas de transição da escola para o trabalho, e programas de emprego apoiado para pessoas com deficiência mental. Dentro desta proposta, dois tipos diferentes de grupos de trabalho estão previstos: o grupo de planejamento de programa na comunidade e o grupo de prestação de serviços.

A racional para o emprego de grupos de planejamento e de prestação de serviços na própria comunidade é dupla. Em primeiro lugar, o trabalho de planejamento entre agências prestadoras de serviços elimina vácuos entre serviços, evita duplicação dos mesmos e potencializa aqueles recursos da comunidade que são escassos. Em segundo lugar, o planejamento transdisciplinar e a formação de grupos de prestação de serviços reduzem a tendência de formação de paróquias de profissionais, contribuindo para aumentar a organização dos serviços e a eficácia da própria prestação de serviços.

Um planejamento de programa na comunidade deve ser entendido como um processo de tomada de decisão racional, consciente e deliberado, por um grupo formal de pessoas (KETTNER et al., 1985 apud EVERSON; MOON, 1990). Este processo apresenta algumas características definidoras. A primeira destas características consiste em um grupo de pessoas interessadas, e que de alguma forma já atuam na comunidade sobre a questão, concordar em servir como agente de mudança. A mudança a ser executada não encontra barreiras dentro do próprio grupo; é exeqüível, é formalizada por escrito e planejada para atingir todos os potenciais usuários com deficiência mental. Esta mudança é direcionada à melhoria da qualidade de vida destas pessoas e avaliada em função desse objetivo. Everson e Moon (1990) apresentam como objetivos do grupo de planejamento de programa na comunidade o de desenvolver a transição da escola para o trabalho e o de desenvolver programas de emprego apoiado. No entanto, tais objetivos sempre serão decorrentes de uma análise bem elaborada das necessidades da comunidade onde os grupos forem formados.

São quatro os passos principais para o desenvolvimento de grupos de planejamento de programas na comunidade: o inicio da formação do grupo; a definição das necessidades da comunidade, a identificação dos elementos do grupo, e o início do seu funcionamento.

A composição do grupo de planejamento de programas pode ser bastante flexível. Dele podem participar profissionais da comunidade das mais variadas áreas do conhecimento (advogados, assistentes sociais, administradores, 
contadores, empresários, economistas, fisioterapeutas, fonoaudiólogos, médicos, psicólogos, pedagogos, professores, terapeutas ocupacionais, etc.), pais, prestadores ou recipientes de serviços já existentes, e pessoas em geral que estejam atuando de forma engajada no planejamento e na melhoria da qualidade desses serviços. $O$ grupo pode ser implantado e organizado por qualquer uma dessas pessoas, ou ainda, por consultores ou assessores externos, tais como: administradores ou professores universitários. Tipicamente, as pessoas que iniciam a composição de um grupo são aquelas que identificam primeiramente uma demanda na comunidade, seja por novos tipos de serviço, seja por mudança no atendimento de serviços já existentes. É esperado e possível que os membros do grupo em formação já tenham discutido a questão extensivamente entre si, e até que já tenham desistido de ir adiante frente à complexidade do problema a ser equacionado e da demanda de habilidades novas e complexas. Para quem identificar esse nicho, o passo seguinte é o de constituir um grupo de planejamento de desenvolvimento de programas ou grupo célula inicial (EVERSON; MOON, 1990).

Uma vez tendo sido constituído o grupo de trabalho, o passo seguinte constitui-se na definição das necessidades da comunidade. Qualquer pessoa pode definir uma necessidade. No entanto, a definição clara desta necessidade é importante porque é o primeiro passo para que a solução para um problema seja encontrada. A definição da necessidade é que leva à clareza do problema e à sua solução. Para se definir a necessidade, portanto, é preciso que o grupo organizado a discuta exaustivamente. De acordo com Santos (1999), uma necessidade inicialmente identificada só se transforma em um problema quando for exaustivamente pensada ou refletida.

Cada comunidade define, dentre os recursos disponíveis, quem deve participar como parceiro do grupo. Consideram-se, neste momento, os recursos, agências, serviços, empresas, instituições, cargos, posições, e não obrigatoriamente as pessoas. Para auxiliar na identificação dos parceiros participantes, pode-se pensar em pais engajados em ações sociais, organizações de assistência ou serviço social e outras específicas da comunidade.

Embora seja necessário um primeiro levantamento, um grupo grande de parceiros participantes pode tornar o empreendimento inoperável. Sendo assim, sugere-se que sejam escolhidos somente os parceiros essenciais, tendo em vista as suas categorias de representação.

O grupo de planejamento de programas na comunidade começa a funcionar a partir da primeira reunião com seus componentes. Para garantir que o início seja bem sucedido, e indicativo de um bom funcionamento posterior do grupo, é preciso que alguns cuidados sejam tomados. Como ainda não se sabem quais as pessoas que irão representar os participantes, um indicador seguro do sucesso do funcionamento do grupo é que todos os participantes enviem representantes para a reunião inicial. Não se pode simplesmente esperar que, após todo o engajamento inicial dos membros que tomaram a iniciativa de compor o 
grupo, os demais participantes potenciais tenham a mesma compreensão da necessidade previamente identificada e da solução proposta e, conseqüentemente, por esta razão, decidam participar da reunião. É importante lembrar que eles deverão ser convencidos a participar, e que este trabalho cabe exatamente à célula inicial do grupo. Algumas iniciativas podem ajudar no êxito da primeira reunião.

Os participantes potenciais devem ser formalmente convidados para participar da reunião planejada. Este convite pode, por exemplo, apresentar o formato de uma carta, devendo ser enviada a todos os potenciais participantes essenciais do grupo. Um primeiro tópico de discussão para a célula inicial do grupo, ou o grupo organizador da reunião, aqui denominado "grupo de planejamento do desenvolvimento de programas na comunidade", é decidir para quem a carta vai ser endereçada. Pode ser aconselhável enviá-la para os líderes, diretores, formadores de opinião, etc., entre os potenciais participantes essenciais. Para facilitar o trabalho na tarefa de decisão sobre sua participação ou não, e na indicação de seu representante, algumas informações importantes devem estar contidas na cartaconvite a este participante potencial. A necessidade identificada, assim como a racional do problema e a formação do grupo enquanto solução para o problema são elementos essenciais do programa. Da mesma forma, os objetivos e as atividades do grupo também são essenciais, pois vão preparar o participante, ajudando-o a planejar sua atuação e o tempo que deverá se dedicar ao projeto. São essenciais, também, a clara exposição da pauta, data, horário (início e previsão de término) e local da reunião e, finalmente, a identificação de uma pessoa de contato, caso o convidado queira obter maiores informações. Esta pessoa é a responsável pelos contatos a serem feitos com os convidados, com a finalidade de confirmar sua presença, ou de conhecer antecipadamente seu representante, etc. A agenda deve privilegiar a troca de informações sobre os participantes, e estes serão devidamente identificados com seus respectivos nomes e representação.

A necessidade da comunidade mais especificamente expressa em termos do problema que o grupo vai debater é retomada e, se possível, detalhada com apresentação de maiores informações. Uma explicação sobre a importância do grupo em formação como solução potencial para o problema é introduzida, assim como a importância do papel de cada um dos representantes dentro do grupo. Novamente, o que se espera dos presentes é retomado e, se possível, detalhado. Antes de encerrar o encontro, os membros do grupo indicam um coordenador, mesmo que seja em caráter temporário, e a data e o local para um segundo encontro. Não é aconselhável que haja encontros muito próximos e nem muito espaçados entre si. Os participantes devem decidir a freqüência inicial, tendo-se sempre claro que é possível rediscuti-la em função da demanda do grupo e da disponibilidade dos seus membros.

É impossível deixar de mencionar que para os integrantes do grupo inicial, em uma etapa imediatamente posterior à reunião, uma avaliação dos resultados deverá ser feita, mesmo que informalmente e, muito possivelmente, até de maneira espontânea. 
Transcorrida a primeira reunião, é tempo de dar início ao planejamento da reunião seguinte. Nesta, o desenvolvimento de uma proposta de ação ocupará um espaço significativo da agenda. Para dar início ao trabalho, Everson e Moon (1990) propõem a definição da missão do grupo de planejamento de programa na comunidade. Entende-se que este passo seja importante, em primeiro lugar, porque se constitui em uma atividade programada para o grupo. Em segundo lugar, é uma atividade que leva ao maior conhecimento sobre os valores básicos do grupo, através da discussão sobre eles, em relação ao problema a ser enfrentado. Em terceiro lugar, faz parte de um planejamento de uma reunião bem sucedida, na medida em que é muito provável que os integrantes do grupo compartilhem os mesmos valores básicos. Sendo assim, pode haver muito a se discutir e, pouco com o que se discordar. Discordâncias no início do trabalho, em geral, tendem a ser contra-producentes e devem ser evitadas.

No planejamento da ação ou no desenvolvimento da proposta de trabalho, mais informações ou dados são levantados, para auxiliar na definição mais precisa das necessidades e conseqüentes tomadas de decisão sobre questões que se apresentarão no futuro. Em seguida, o grupo de planejamento de programas na comunidade elabora um levantamento de perguntas relevantes sobre as necessidades da comunidade. Os procedimentos de levantamento e a profundidade com que se pretende chegar com cada um deles é decisão de cada um dos grupos.

A partir das informações coletadas a respeito das necessidades da comunidade, o passo seguinte é estabelecer objetivos para o programa de mudança. Este é um passo crucial, pois tende a mudar o enfoque do grupo de questões passadas para questões futuras relacionadas aos serviços que serão programados para atender essas necessidades, e para os resultados esperados dos mesmos. Com os objetivos claramente definidos, os resultados de curto prazo são identificados, o que ajuda a manter o funcionamento do grupo.

Everson e Moon (1990) ressaltam quatro componentes importantes dos objetivos dos grupos de planejamento de programas na comunidade: elaboração de um cronograma de resultados; identificação da população-alvo; identificação de resultados a serem alcançados e proposição de critérios de avaliação dos trabalhos. O envolvimento de todo o grupo na redação, discussão e revisão dos objetivos, com a garantia de condições necessárias pelo coordenador, aumentam a probabilidade de que os objetivos sejam alcançados. Após a identificação dos objetivos e de terem sido aceitos pelo grupo, por unanimidade, as atividades específicas para que sejam alcançados serão elaboradas. Após o esclarecimento da missão do grupo, da identificação de seus objetivos e da elaboração das atividades, o grupo estará pronto para dar início ao processo de mudança na comunidade.

Todo o trabalho anterior não é bem sucedido se não for acompanhado de monitoramento cuidadoso das atividades e de uma avaliação do grau de sucesso com que essas atividades são desenvolvidas. Portanto, é também de fundamental importância que todo o processo de avaliação seja claramente definido. Existem 
muitas razões pelas quais problemas podem surgir na implementação de um programa. Quanto mais cedo esses problemas forem identificados, e alternativas adequadas serem implantadas, tanto maior será a probabilidade de que esse programa, como um todo, seja bem sucedido. Para tanto, as avaliações serão peças fundamentais para que o grupo possa identificar e corrigir os problemas encontrados.

Simultaneamente ao processo de planejamento de programa na comunidade e, mais provavelmente, após a identificação dos objetivos, das atividades do grupo e da população-alvo, é o momento adequado para se planejar o desenvolvimento de grupos de prestação de serviços individuais. Esses grupos têm como responsabilidade conduzir a política gerada pelo grupo de planejamento de programa na comunidade. Em geral, a montagem desses grupos se espelha na montagem do grupo de planejamento de programa, anteriormente descrita. A começar pela sua composição, qualquer membro da comunidade poderá fazer parte, principalmente, aqueles que já atuam na área, oferecendo apoio ou treinamento à população-alvo. Os grupos de prestação de serviços também têm valores comuns e devem trabalhar de acordo com eles. São de fundamental importância a coleta de informações sobre as necessidades da população-alvo, a identificação de objetivos e de atividades para essa população, e a discussão das informações, dos objetivos e das atividades, com os membros do grupo de planejamento de programa na comunidade e, também, a avaliação concreta do trabalho. Em vários países, as pessoas com deficiência mental obrigatoriamente têm seu plano individualizado de transição ou o plano individualizado de reabilitação, por escrito. Na sua ausência, a criação do plano individualizado de reabilitação pode se constituir em objetivo (EVERSON; MOON, 1990).

A proposta de ação apresentada acima, baseada em Everson e Moon (1990) é apresentada como uma alternativa para se abordar um problema considerado como de difícil solução na realidade brasileira (GOYOS, 1995). No entanto, esta proposta ainda carece de validação na realidade brasileira e considerase de fundamental importância, neste caso, que haja replicação do procedimento em comunidades diferentes daquelas onde a proposta foi inicialmente desenvolvida. Neste contexto, o presente estudo tem por objetivos replicar o procedimento descrito por Everson e Moon (1990), e descrever e analisar o processo de formação de um grupo de planejamento de programa de suporte comunitário para o trabalho do adulto com deficiência mental, em uma comunidade do interior do estado de São Paulo, tendo em vista a necessidade de preparação, encaminhamento, colocação e suporte desta pessoa no ambiente natural de trabalho. 


\section{Método}

\section{Participantes}

Grupo de Planejamento do Desenvolvimento de Programas na Comunidade: Participaram dois pesquisadores com formação em Psicologia, e quatro auxiliares de pesquisa com graduação em Pedagogia.

Grupo de Planejamento de Programa de Suporte Comunitário: Participaram representantes de setores considerados expressivos de uma cidade de porte médio do interior paulista: Diretoria Regional de Ensino (dois supervisores de ensino); Sub-delegacia do Trabalho (dois assistentes jurídicos); SENAI (um agente de treinamento e uma assistente social); Associação de Esportes para Cegos (um membro da diretoria); uma representante (diretora) das instituições de ensino especial; um dos pesquisadores (a primeira autora), e as quatro auxiliares de pesquisa, totalizando 13 participantes que compuseram o referido grupo.

\section{LOCAL}

O Grupo de Planejamento do Desenvolvimento de Programas na Comunidade se reuniu com a finalidade de planejar as reuniões em uma sala destacada para esta finalidade, localizada em um dos laboratórios do Departamento de Psicologia, da Universidade Federal de São Carlos (UFSCar).

O Grupo de Planejamento de Programa de Suporte Comunitário se reuniu em locais variados, conforme a disponibilidade das instituições participantes. Ocorreram reuniões em uma das dependências de um centro universitário particular; na sede local da Sub-delegacia do Trabalho e na sede local do SENAI. As reuniões foram realizadas em salas existentes nas instituições citadas, preparadas para esta finalidade.

\section{MATERIAL}

Com relação ao Grupo de Planejamento do Desenvolvimento de Programas na Comunidade: O material para a coleta de dados, nas reuniões do referido grupo, consistiu de 01 filmadora, micro-fitas de vídeo, folhas de papel sulfite e caneta.

Com relação ao Grupo de Planejamento de Programa de Suporte Comunitário: O material para a coleta de dados, nas reuniões do referido grupo, consistiu de 01 gravador de áudio, micro-fitas de vídeo, folhas de papel sulfite e caneta.

\section{Delineamento da Pesquisa}

Do ponto de vista metodológico, a presente pesquisa caracterizou-se pela metodologia participativa ou de tipo "pesquisa-ação". A pesquisa-ação é definida como um tipo de pesquisa organizada de modo participativo, com a colaboração de 
pesquisadores e membros ou grupos implicados em determinada situação ou prática social. A colaboração dos participantes da pesquisa é estabelecida a partir de um "contrato", no qual são definidos os objetivos gerais do projeto e as modalidades de organização e de apoio, "de modo a identificar os problemas, buscar soluções e implementar possíveis ações coletivamente deliberadas" (THIOLLENT, 2000, p. 56).

Todos os membros do grupo de planejamento de programa de suporte comunitário participaram ativamente do processo de tomada de decisões desde a definição dos objetivos da pesquisa e da própria formação do referido grupo; a identificação das necessidades da comunidade no que tange ao trabalho da pessoa com deficiência mental, visando a caracterização do problema e previsão dos resultados a serem alcançados; decisão sobre a freqüência com que o grupo deveria estabelecer suas reuniões em função da demanda do mesmo e da disponibilidade de seus membros até a definição das atividades e da população-alvo. Todos tiveram, igualmente, a oportunidade de avaliar, parcial e integralmente, o processo desenvolvido.

\section{Procedimento de coleta dos dados}

Com relação ao Grupo de Planejamento do Desenvolvimento de Programas na Comunidade: Seis reuniões foram realizadas com os objetivos de constituir o grupo (primeira reunião) e de planejar os passos abaixo relacionados, visando à realização das reuniões do grupo de planejamento de programa de suporte comunitário (EVERSON; MOON, 1990):

Passo 1: Iniciando a equipe;

Passo 2: Definindo a necessidade da comunidade;

Passo 3: Identificando membros da equipe;

Passo 4: Planejando o encontro inicial do grupo;

Passo 5: Definindo a missão do grupo de planejamento de programa na comunidade;

Passo 6: Avaliando as oportunidades de mudança;

Passo 7: Estabelecendo objetivos e atividades;

Passo 8: Acompanhando e avaliando os esforços de mudança.

Durante as reuniões do grupo de planejamento do desenvolvimento de programas na comunidade, era refletida e discutida a leitura prévia do texto das autoras acima citadas, no que tange aos passos propostos, buscando definir seus objetivos, conteúdo, estratégias para promover a participação dos membros do grupo e para avaliação da consecução ou não dos objetivos estabelecidos. As reuniões deste grupo consistiram na identificação e planejamento dos Passos 1 a 7 , conforme anteriormente mencionados. Portanto, cada reunião foi planejada e implementada, obedecendo-se a seqüência proposta por Everson e Moon (1990).

Todas as reuniões do grupo de planejamento do desenvolvimento de programas na comunidade foram gravadas em vídeo e procedeu-se à transcrição dos registros. As informações eram confrontadas, a fim de verificar a confiabilidade 
dos dados obtidos, com o objetivo de preservar e garantir a integridade das informações fornecidas.

Descrição da Dinâmica das Reuniões do Grupo de Planejamento do Desenvolvimento de Programas na Comunidade: As reuniões do grupo tiveram duração aproximada de uma hora e trinta minutos. Cada reunião teve por objetivo planejar as reuniões do grupo de programa de suporte comunitário, de acordo com a seqüência de passos proposta por Everson e Moon (1990). Sendo assim, a definição de cada passo constituía-se no objetivo de cada reunião realizada.

Inicialmente, estabelecia-se e o objetivo de cada reunião e discutia-se a leitura correspondente ao passo programado. Com base nesta discussão, propunhase o conteúdo a ser apresentado na reunião seguinte com o grupo de planejamento de programa de suporte comunitário. Estabelecia-se, igualmente, o curso da dinâmica da reunião no tocante ao encaminhamento das discussões no grupo, bem como, as estratégias para promover a participação e para avaliar a consecução ou não dos objetivos propostos, ao final da mesma.

Após cada reunião com o grupo de planejamento de programa de suporte comunitário, o grupo de planejamento do desenvolvimento de programas na comunidade se reunia, para avaliar os resultados obtidos no que concerne à consecução dos objetivos definidos para a reunião; possíveis dificuldades encontradas, entre outros aspectos. Tal avaliação possibilitou redirecionar o planejamento das reuniões seguintes.

Com relação ao grupo de planejamento de programa de suporte comunitário: Foram realizadas oito reuniões com os objetivos de constituir o grupo (primeira reunião) e de implementar os passos propostos por Everson e Moon (1990), visando a formação de um programa de suporte comunitário no que tange à preparação, encaminhamento, colocação e apoio ao adulto com deficiência mental para o trabalho.

As reuniões do grupo foram registradas manualmente por participantes do grupo de planejamento para se tentar garantir a totalidade das informações fornecidas e, ao final das reuniões, os registros obtidos foram comparados, a fim de verificar o grau de concordância entre os observadores. Considerou-se, para isso, a seqüência de apresentação das falas dos membros do grupo, em cada uma das reuniões realizadas.

A primeira reunião do grupo objetivou a implementação dos passos 1 a 4 e, a segunda reunião, teve por objetivo a implementação do passo 5. Foram necessárias quatro reuniões para completar o passo 6 e duas reuniões para finalizar o passo 7 .

Na primeira reunião, os membros do grupo célula inicial apresentaramse e elegeram um dos pesquisadores como coordenador do grupo. Solicitou-se que todos os membros, igualmente, se apresentassem, considerando-se sua identificação pessoal, instituição de origem, expectativas e motivos do encontro inicial. 
Foram apresentados os objetivos da proposta de trabalho, buscando averiguar o interesse e a disponibilidade dos representantes presentes quanto à consecução da mesma. Em seguida, contextualizaram-se as principais necessidades da comunidade local e, no âmbito mais amplo, aquelas referentes à preparação, encaminhamento, colocação e suporte ao adulto com deficiência mental, conforme anteriormente mencionadas. Tais necessidades foram levantadas a partir de informações sobre a comunidade local no que tange aos aspectos acima indicados, bem como, a partir da análise da literatura da área.

Os representantes presentes consideraram legítimas as necessidades levantadas no tocante à comunidade local, tendo em vista a implementação de serviços preparatórios do adulto com deficiência mental para o trabalho.

Nesta reunião, solicitou-se a anuência dos representantes presentes para que o trabalho a ser desenvolvido fosse conduzido sob a forma de pesquisa, tendo em vista a produção compartilhada do conhecimento sistematizado, a fim de colocálo à disposição de outras comunidades, cujas necessidades sejam similares às apresentadas pela comunidade local, caso os resultados obtidos forem positivos. Consideraram-se os padrões éticos que devem reger a conduta dos pesquisadores e as relações com e entre os participantes da mesma tais como: observância quanto ao cumprimento das regras definidas no grupo; manutenção da integridade das informações obtidas; utilização das informações para fins científicos e em beneficio dos participantes e da pessoa com deficiência mental alvo do estudo.

Buscou-se estimular a participação de todos os membros, enfatizando a importância de refletir, discutir, apresentar considerações e sugestões que indicassem o posicionamento pessoal de cada membro do grupo. Também foram incentivadas as falas que convergiam para a direção da discussão pretendida.

Os representantes presentes sugeriram que outros representantes de instituições expressivas na comunidade deveriam compor o referido grupo, tais como, FIESP/CIESP, um representante dos pais e o próprio adulto com deficiência mental. Consideraram, também, que se deveria insistir no convite aos representantes ausentes, embora já tivessem sido convidados.

Antes de terminar a reunião, combinou-se a reunião seguinte do grupo, num prazo de três semanas. Definiu-se também o local, de acordo com a iniciativa de um dos membros do grupo.

Os membros do grupo comprometeram-se em enviar carta-convite, para cada reunião, acrescida de uma síntese da discussão do grupo e que seria enviada a todos os participantes, e também aos convidados ainda não participantes. Visando manter a freqüência dos participantes que sempre compareciam às reuniões, a cartaconvite era enviada antes de cada reunião, agradecendo as contribuições oferecidas e, aos convidados ainda não participantes, indicava-se a ausência, apontando a importância de sua presença no grupo. A partir da terceira reunião os representantes de instituições que permaneciam ausentes, não mais eram convidados a participar. 
Esta síntese indicava, inicialmente, a data, horário e local onde ocorreu a reunião; representantes presentes; retomada dos objetivos da mesma; resumo das discussões conduzidas pelo grupo e principais decisões tomadas; indicação dos representantes ausentes; data, horário (previsão de início e término) e local da próxima reunião; disponibilização dos telefones de contato e assinatura da pesquisadora juntamente com a identificação do grupo.

Insistia-se em mostrar a importância da presença de todos os membros do grupo nas reuniões seguintes, apresentando-se oralmente as contribuições que o referido grupo poderia oferecer no que tange à criação de um sistema comunitário de apoio para o trabalho do adulto com deficiência mental. Tais contribuições focalizaram a relevância da construção de uma rede de relações entre quem oferece o treino para o trabalho (escolas especiais e outras agências de formação); quem oferece o emprego (empresários) e quem vai oferecer o suporte (especialistas no trabalho). Os representantes presentes se dispuseram a continuar no grupo, bem como, participar das reuniões seguintes.

Na segunda reunião, buscou-se a implementação do Passo 5: “Definindo a missão do grupo de planejamento de programa de suporte comunitário". As reuniões seguintes foram destinadas à implementação do Passo 6 "avaliação das oportunidades de mudança" (quatro reuniões) e ao Passo 7 "estabelecimento de objetivos e atividades" (duas reuniões), conforme anteriormente mencionado.

Durante todas as reuniões, os representantes presentes foram incentivados, considerando-se os aspectos anteriormente expostos, a refletir e discutir sobre a importância da formação do referido grupo como possível parte da solução para as necessidades detectadas quanto aos serviços de preparação, encaminhamento, colocação e suporte ao adulto com deficiência mental para o trabalho, tendo em vista a transição do mesmo da escola especial para o mercado de trabalho e a definição e planejamento de procedimentos voltados para o emprego apoiado.

Descrição da Dinâmica das Reuniões do Grupo de Planejamento de Programa de Suporte Comunitário: Cada reunião do referido grupo teve por objetivo implementar a seqüência dos passos propostos. Sendo assim, a implementação de cada passo constituía-se no objetivo de cada reunião, que era iniciada pela retomada das decisões da reunião anterior, conforme a síntese encaminhada previamente aos participantes junto à carta-convite e apresentavam-se os objetivos da nova reunião.

Lembrava-se, em todas as reuniões, a missão do grupo. A missão definida passou a ser o parâmetro em relação ao qual as discussões convergiam, tendo em vista as necessidades que estavam sendo identificadas.

Estimulava-se a participação de todos os membros do grupo, reforçando (elogiando, parafraseando, solicitando maiores informações, elaborando novas 
questões visando maior aprofundamento) as falas dos mesmos que apontavam para as direções desejadas.

Finalizava-se cada reunião, solicitando-se aos participantes que avaliassem se os objetivos propostos para a mesma foram atingidos e, em caso negativo, discutia-se sobre prováveis fatores que deveriam ter inviabilizado a consecução dos mesmos, assim como todas as decisões eram tomadas consensualmente no grupo.

Os participantes também assinavam uma lista de presença, em momento próximo ao término da reunião. A referida lista continha informações sobre o número da reunião; nome do grupo; local; data; horário; uma coluna para escrever o nome e, outra coluna, correspondente ao espaço para a assinatura do participante.

\section{Procedimento de ANálise de dados}

Elaborou-se o procedimento para análise dos dados coletados junto às reuniões do grupo de planejamento de programa de suporte comunitário, baseandose na análise de conteúdo (BARDIN, 1977) dos passos propostos e das falas dos participantes do referido grupo. Com base nos registros manuais foram destacados os aspectos convergentes e divergentes das mesmas referentes ao processo de formação de um programa de suporte comunitário.

Com base nesta análise, foram levantados onze "aspectos de conteúdo", a saber: confirmação da presença; justificativa da ausência; formação da equipe; presença ou ausência do representante à reunião; objetivos da reunião; local; horário (início e término); missão do grupo; necessidades levantadas; soluções apontadas; avaliação das reuniões quanto ao cumprimento dos objetivos propostos, tendo em vista os passos anteriormente planejados.

\section{Resultados E Discussão}

Os resultados apresentados sob a forma descritiva, e organizados de acordo com "aspectos de conteúdo", encontram-se relacionados em seguida. O Quadro 1 mostra a distribuição da freqüência dos participantes às reuniões do grupo. 
Quadro 1 - Freqüência individual e total (em porcentagem) dos participantes nas reuniões do grupo, identificadas pelos temas abordados.

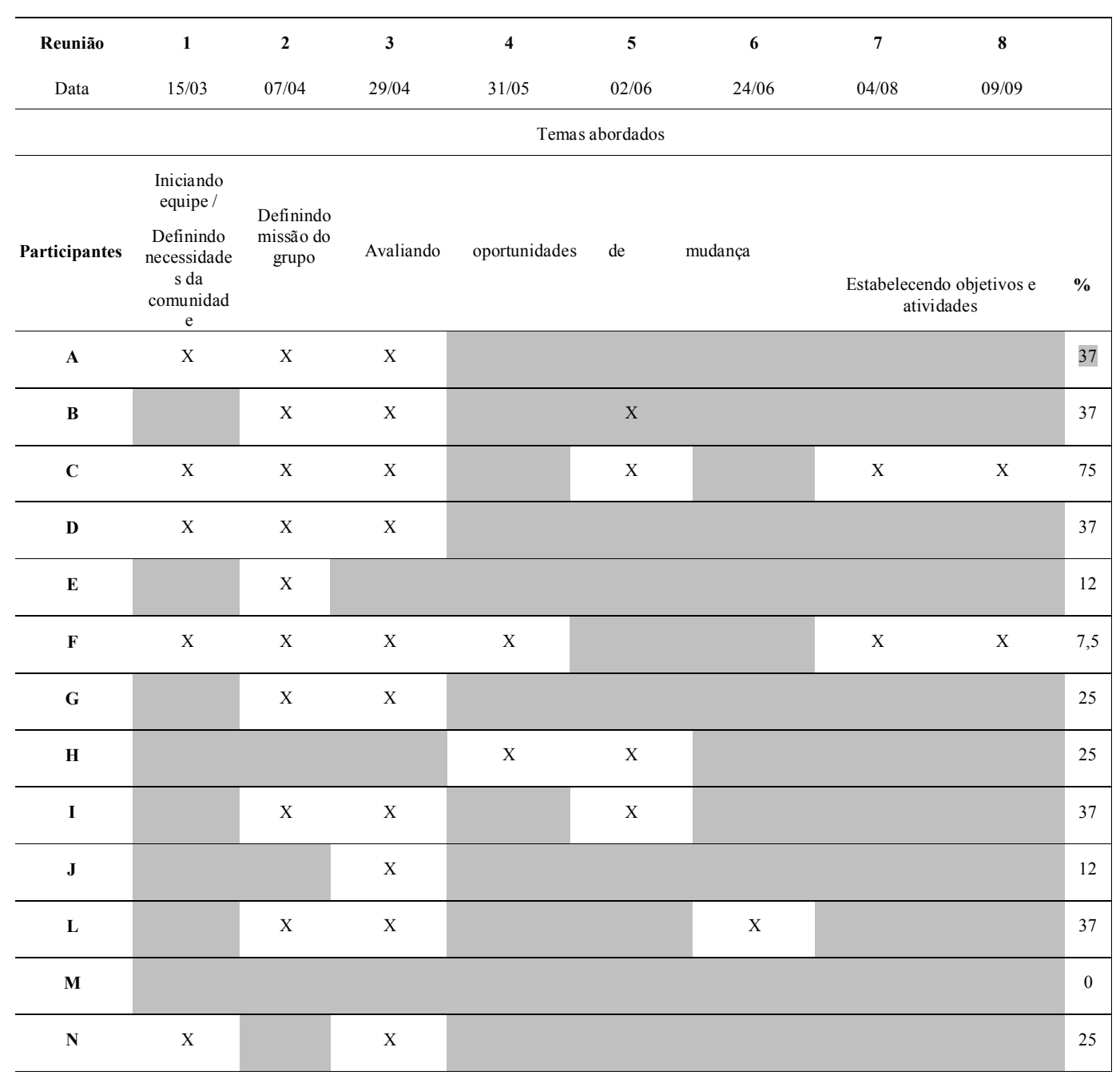

Com relação à formação da equipe: Inicialmente, as instituições potenciais parceiras foram indicadas, por ocasião do planejamento realizado no grupo de planejamento de desenvolvimento de programas na comunidade.

A primeira reunião do grupo de planejamento de programa de suporte comunitário contou com a participação de representantes da Diretoria Regional de Ensino, do SENAI, da Sub-delegacia de Trabalho, da UNICENP/ASSER e do próprio grupo de planejamento do desenvolvimento de programas na comunidade. Na segunda reunião, estiveram presentes os representantes da Diretoria Regional de Ensino, do SENAI, Escola Especial; Sub-delegacia do Trabalho, Associação de Esportes para Cegos (que fora convidada por um dos representantes da Diretoria 
Regional de Ensino) e do próprio grupo de planejamento do desenvolvimento de programas na comunidade. A partir da segunda reunião, os membros do grupo consideraram a importância da participação do representante da FIESP/CIESP, no grupo.

Com relação à confirmação da presença às reuniões: Apenas uma das instituições confirmou sua participação com antecedência, através de um dos telefones disponibilizados para contato, em relação à primeira reunião que visou a formação do referido grupo. Os representantes das demais instituições não confirmaram suas participações nas reuniões posteriores, porém, compareceram às mesmas.

Com relação à justificativa da ausência às reuniões: Apenas uma das instituições cujos representantes foram convidados, justificou sua ausência da reunião com antecedência, através de um dos telefones disponibilizados para contato. Na justificativa foi informado que a gerente geral encontrava-se em férias e seu substituto não poderia participar da mesma, visto ter assumido outro compromisso, fora do município, mas que sua participação ou de outro representante da instituição estaria confirmada para a reunião seguinte. Entretanto, a referida instituição não foi representada nas reuniões seguintes do grupo.

Com relação à presença/ausência do representante às reuniões: Na primeira reunião, estiveram ausentes os representantes do SEBRAE, SENAC, Secretaria Municipal de Educação - Setor de Educação Especial, Escola Especial. Na segunda reunião, estiveram ausentes os representantes da UNICENP/ASSER, SEBRAE, SENAC e Secretaria Municipal de Educação - Setor de Educação Especial. Convém lembrar que só o representante do SEBRAE justificou sua ausência apenas em relação à primeira reunião do grupo, conforme anteriormente mencionado.

Quanto ao local das reuniões: Cada instituição parceira sediou um encontro do grupo.

Quanto ao horário das reuniões: a primeira reunião ocorreu no período noturno, das 20:00h às 21:30h. As demais reuniões ocorreram no período vespertino, das 14:00h às 15:30h.

Com relação aos objetivos da reunião: O objetivo geral da primeira reunião, exposto imediatamente após seu início, foi apresentar uma proposta de montagem de serviço, visando a preparação, encaminhamento, colocação e apoio do adulto com deficiência mental para o trabalho na comunidade local, através da formação de um grupo de planejamento de programa de suporte comunitário. Tal objetivo passaria a nortear todas as reuniões do referido grupo. Os objetivos específicos consistiram em: "introduzir os membros do grupo (formal e informalmente), indicando quem são e a quem representam; justificar o convite para cada instituição representada; descrever a necessidade percebida na comunidade, buscar dados na comunidade para documentar as necessidades percebidas, estabelecer a "racional" de uma equipe de planejamento de programas na comunidade; nomear o 
coordenador (pesquisadora); combinar nova data, horário (início e término) e local para o segundo encontro do grupo".

A segunda reunião teve por objetivo específico estabelecer a missão (base de valores) do grupo, visando um plano de ação para o desenvolvimento de serviços voltados para o treinamento, preparação, encaminhamento e manutenção do adulto com deficiência mental no trabalho, apoiado em programas de suporte comunitário.

Com relação à missão do grupo:

"eu acho que o grupo deve funcionar como a cabeça pensante de todo o processo e oferecer uma política de atuação para o grupo" (representante da Sub-delegacia do Trabalho)

Consistiu, segundo os participantes do grupo, em buscar e organizar parcerias, visando identificar necessidades, o planejamento e a integração de serviços, além de administrar a participação de vários setores da comunidade local potencialmente envolvidos na implementação dos referidos serviços. A preocupação do grupo recaiu sobre os mecanismos que garantam a qualidade dos serviços e o compromisso com a atuação competente da pessoa com deficiência mental no ambiente natural de trabalho, tendo, como cidadão, seus direitos assegurados e respeitados.

Tal missão passou a nortear as discussões do grupo, bem como auxiliou na detecção de necessidades, visando avaliar as oportunidades de mudança, objeto das discussões do grupo nas reuniões seguintes.

\section{Com relação às necessidades levantadas:}

"Não adianta o empresário contratar, se o indivíduo deficiente mental não for preparado para o trabalho" (representante do SENAI).

Foram levantadas as necessidades referentes à formação do grupo propriamente dita e as necessidades levantadas em relação ao desenvolvimento de serviços preparatórios, de encaminhamento, de colocação e de apoio ao trabalho do adulto com deficiência mental. No tocante à formação do grupo de planejamento de programa de suporte comunitário, a partir da primeira reunião, o referido grupo insistiu na participação do representante do FIESP/CIESP, um representante dos pais dos adultos com deficiência mental que freqüentam a Escola Especial e um representante dos próprios usuários adultos com deficiência mental. Convém informar que o representante da FIESP/CIESP compareceu apenas na terceira reunião do grupo e o representante dos pais e o próprio adulto com deficiência mental, ainda não compareceram ao grupo, embora a representante da escola especial relatasse tê-los convidado e insistido para que participassem do grupo.

No que tange às necessidades levantadas em relação ao desenvolvimento de serviços preparatórios para o trabalho, os representantes presentes concordaram com a identificação das necessidades apontadas pelo grupo de planejamento de desenvolvimento de programas na comunidade. 
Com relação às soluções parcialmente apontadas:

não adianta se no preparo do deficiente mental se não se pensar no preparo do profissional que vai treiná-lo (representante da Diretoria Regional de Ensino).

Para atender às necessidades detectadas, tendo em vista a missão definida pelo grupo, algumas prováveis soluções foram apontadas, considerandose a tomada de decisões para a definição futura de um plano de ação com base na avaliação das oportunidades de mudança que serão futuramente delineadas, a saber: os participantes manterem-se como membros parceiros do grupo de planejamento de programa de suporte comunitário; insistir no convite aos demais representantes previamente indicados que se mantêm ausentes; estender o convite ao representante da FIESP/CIESP local, bem como outros representantes junto aos empresários para comporem o referido grupo; o representante da Sub-delegacia do Trabalho tomou a iniciativa de proceder ao levantamento das empresas que apresentam mais de cem funcionários no município e região, cuja legislação ("Lei de Cotas") obriga a contratação de pessoas com deficiência. Tal levantamento mostrou que são 70 empresas no município e 107 empresas na região como um todo, totalizando 177 empresas. Considerou que, em breve, estará levantando as empresas que já estão realizando tal contratação, bem como, o índice de pessoas contratadas, por modalidade de deficiência. Informou, também, que estará se reunindo com os dirigentes de cada empresa, buscando sensibilizá-los para a contratação de funcionários com deficiência mental. O grupo considerou a necessidade de planejar, implementar e avaliar um curso de formação de profissionais para o treino e acompanhamento sistemáticos do adulto com deficiência mental no ambiente natural de trabalho. Tal necessidade mostrou-se prioritária para o grupo, uma vez que a literatura (EVERSON; MOON, 1990; GOYOS, 2001) e a própria experiência pessoal dos participantes do mesmo tem mostrado a falta de preparo dos profissionais que se dispõem a treinar a pessoa com deficiência mental para o trabalho. A partir das necessidades detectadas, o grupo levantou prováveis disciplinas que poderiam compor o curso, bem como, os tópicos que poderiam ser abrangidos em cada uma delas, definindo-se os objetivos gerais e específicos do curso. A proposta do curso foi encaminhada aos membros do grupo célula inicial que decidiu pelo planejamento do mesmo, considerando sua oferta sob a forma de curso de aperfeiçoamento e de extensão à comunidade, com carga horária de 180 horas. O projeto do curso foi elaborado e encaminhado ao Departamento de Psicologia da UFSCar e, após ser aprovado nesta instância e em outras pertinentes à Universidade, foi implementado e está em andamento, tendo recebido trinta alunos inscritos. Do referido curso, pretende-se derivar o grupo de prestação de serviços, na comunidade local. Os resultados a serem obtidos, ao final do curso, contribuirão para que se avalie o passo 8: "acompanhando e avaliando as oportunidades de mudança".

Com relação à avaliação das reuniões quanto ao cumprimento dos objetivos propostos, tendo em vista os passos anteriormente planejados. 
acho que atingimos os objetivos a que nos propomos, mas é ainda necessária a participação de representantes de outros setores da comunidade, como por exemplo, a Prefeitura Municipal e seu empenho em colaborar com a solução desse Problema. (representante de escola especial)

Os participantes eram questionados a respeito do quanto que os objetivos previstos no início de cada reunião tinham sido atingidos ou parcialmente atingidos. Neste sentido, as reuniões foram avaliadas positivamente no que tange ao cumprimento dos objetivos propostos. Considerou-se que os objetivos foram cumpridos, embora houvesse ainda necessidade de mais discussões quanto às soluções apontadas e outras que, porventura possam surgir, visando a tomada de decisões pelos membros do grupo e tendo em vista a participação de outros potenciais parceiros, conforme anteriormente mencionados.

A despeito dos resultados obtidos indicarem avaliação positiva do processo, de acordo com os participantes, devido à consecução dos objetivos propostos nos passos implementados, foram observadas grandes dificuldades na manutenção do grupo, o que impossibilitou a continuidade do trabalho, da maneira como inicialmente fora planejado. Algumas dificuldades podem ser apontadas, tais como: a falta de tradição na realização de um trabalho coletivo, envolvendo varias instituições expressivas da comunidade local; busca de uma intervenção prática imediata, em pouco tempo, sem a necessária reflexão e discussão para o planejamento da mesma; descrédito na potencialidade do trabalho proposto e na capacidade do adulto com deficiência mental em situação de trabalho; outros compromissos assumidos pelos participantes do grupo; interrupção devido a férias e dificuldade das pessoas retornarem às reuniões, após longo período de afastamento.

Além das considerações acima expostas, algumas recomendações são necessárias visando o êxito das reuniões e a manutenção da presença e colaboração dos participantes que comporão o grupo de planejamento de programa de suporte na comunidade, conforme puderam ser identificadas no presente estudo, a saber: a) critérios para seleção do representante: deve-se conhecer os critérios através dos quais o representante da instituição - potencial parceira - é escolhido para a reunião do grupo. É importante conhecer se tais critérios baseiam-se na disponibilidade do representante para participar das reuniões; interesse pela temática; confiança do responsável pela instituição ou até outro critério de natureza aleatória. Para obter os referidos dados, pode-se pensar na elaboração e aplicação de um breve roteiro de entrevista junto ao representante-participante do grupo ou junto ao próprio responsável pela instituição, solicitando que informe os motivos pelos quais o representante foi eleito; b) reuniões setoriais: propor a realização de reuniões iniciais por categorias de profissionais e/ou institucionais, que se deseja como potenciais parceiros, para a composição do grupo de planejamento de programas na comunidade, a partir das quais um representante de cada instituição possa ser indicado. Sendo assim, pode-se programar reuniões junto aos empresários, junto às instituições especiais, entre outras categorias responsáveis pela formação da 
pessoa com deficiência mental, na comunidade, visando sua inserção no ambiente real e integrado de trabalho; c) ajuste do modelo proposto às necessidades da comunidade local: a composição do grupo de planejamento de programas na comunidade deve estar de acordo com as características e especificidades de cada comunidade para a qual o grupo foi indicado como provável solução para os problemas da formação da pessoa com deficiência mental para o trabalho; d) proposição de novos estudos de replicação do modelo: o modelo proposto por Everson e Moon (1990) e sua utilização no presente estudo também está sendo replicado através de um curso de extensão/ aperfeiçoamento de profissionais, das mais diversas áreas, que se dispõem à tarefa de preparar a referida pessoa para o mercado de trabalho. Como tais profissionais provém de várias localidades do estado de São Paulo, espera-se que tenham a oportunidade de serem agentes multiplicadores do referido modelo, em suas comunidades locais.

\section{Conclusão}

De acordo com a proposta apresentada por Everson e Moon (1990), buscou-se replicar os passos indicados pelas autoras para a formação e organização de um grupo de planejamento de programa de suporte comunitário, visando o desenvolvimento de serviços preparatórios do adulto com deficiência mental para o trabalho, na realidade local.

Foram implementados os sete passos principais para o desenvolvimento de grupos de planejamento de programas na comunidade, a saber: o início da formação do grupo; a definição das necessidades da comunidade, identificação dos elementos do grupo e início de seu funcionamento propriamente dito.

Fatores que contribuíram para o êxito do grupo e que também foram apontados na literatura da área como relevantes são: reuniões previamente planejadas, discussão passo a passo das necessidades identificadas, presença periódica dos parceiros às reuniões; tomada conjunta de decisões e criação de um sistema motivacional para criar condições para garantir a participação dos mesmos. A cada reunião era enviada a carta-convite, juntamente com uma síntese do que fora discutido na reunião anterior. Os objetivos de cada reunião eram apresentados e esclarecidos no início de cada reunião. Incentivava-se a participação de todos os membros do grupo, enfatizando que o mesmo pode ser visto como uma solução potencial para os problemas identificados. Também eram incentivadas as falas que apontavam na direção da identificação de problemas e de suas possíveis soluções. Como visto, estes foram fatores necessários, mas não suficientes para a consecução plena dos objetivos propostos.

Os participantes, igualmente, tiveram a possibilidade de decidir a freqüência com que consideram ser desejável a ocorrência das reuniões, cabendo lembrá-los que reuniões muito espaçadas ou muito próximas não são aconselháveis. Um outro aspecto motivacional que foi considerado importante refere-se à oportunidade que os participantes tiveram de avaliar os resultados da reunião, ao 
final das mesmas, discutindo se os objetivos propostos no início da reunião foram integralmente atingidos.

Considerou-se que cada etapa do trabalho se constituiu em preciosa oportunidade para a pesquisa, uma vez que está sendo possível gerar um conhecimento novo, considerando-se a aplicabilidade prática dos resultados produzidos dentro dos moldes da pesquisa participante ou pesquisa-ação, o que também possibilita sua replicação em novas comunidades.

\section{REFERÊNCIAS}

BARDIN, L. Análise de conteúdo. São Paulo: Edições 70, 1977.

EVERSON , J. M.; MOON, M. S. Developing community program planning and service delivery teams. In: RUSH, F. R. (Ed.). Supported employment: models, methods, and issues. Sycamore, IL: Sycamore Publishing, 1990.

GOYOS, A. C. DE N. A profissionalização de indivíduos deficientes mentais. São Carlos, SP: EDUFSCar, 1995.

GOYOS, C. Formação de programa comunitário de suporte para o trabalho do indivíduo com deficiências. In: MARQUEZINE, M. C.; ALMEIDA, M. A.; TANAKA, E. D. O. (Orgs.). Perspectivas multidisciplinares em educação especial II. Londrina: Editora UEL, p. 645-654, 2001.

KETTNER, P.; DALEY, J. M.; NICHOLS, A. E. Initiating change in organizations and communities. Monterey, CA: Brooks/Cole, 1985.

KREGEL, J.; WEHMAN, P. Supported Employment: A decade of employment outcomes for individual with significant disabilities. In: KIERMAN, W. E.; SCHALOCK, R. L. (Eds.). Integrated Employment: current status and future directions. Washington, D.C.: American Association on Mental Retardation, 1997.

RUSCH, F. R. Supported Employment: Models, Methods, and Issues. Sycamore, Ill: Sycamore Publishing Company, 1990.

SANTOS, A.R. Metodologia científica: a construção do conhecimento. Rio de Janeiro: DP\&A Editira, 1999.

TANAKA, E. D. O. O portador de deficiência mental: considerações acerca da sua preparação para o trabalho. In: MARQUEZINE, M. C.; ALMEIDA, M. A.; TANAKA, E. D. O. (Orgs.). Perspectivas multidisciplinares em educação especial II. Londrina: Editora UEL, p. 655-658, 2001.

THIOLLENT, M. A metodologia participativa e sua aplicação em projetos de extensão universitária. In: THIOLLENT, M.; FILHO, T. DE ARAÚJO; SOARES, E R. L. S. (Orgs.). Metodologia e Experiências em Projetos de Extensão. Niterói, RJ, EdUFF, 2000.

Recebido em 27/07/2006

Aceito em 30/08/2006 